JAAKFE 1

Vol.10, No.1 des 2020, hal 1-9

Ilhamadi

\title{
PERAN PEBANKAN SYARIAH TERHADAP PERTUMBUHAN EKONOMI DI INDONESIA
}

\author{
ILHAMDI \\ Institut Agama Islam Negeri Pontianak \\ ilhamdi@iainptk.ac.id
}

\begin{abstract}
$\underline{\text { ABSTRACT }}$
This study aims to determine the role of Islamic banking on economic growth in Indonesia and to compared it with conventional banks. In recent years, Islamic banking has increased in terms of assets. By using panel data regression, this study examines the effect of Islamic banking on economic growth. Besides that, how big is the level of elasticity to economic growth. This study uses secondary data in the form of Gross Domestic Product (GDP), Islamic banking financing and credit by conventional banks. The results showed that Islamic banking and conventional banks had a positive impact on economic growth with the level of elasticity of Islamic banking still below conventional banks. So the existence of Islamic and conventional banks does not always replace, but complement each other in Indonesia.
\end{abstract}

Keyword: Islamic banking, economic growth, Gross Domestic Product (GDP), conventional banks, study examines the effect of Islamic banking

\section{,1. PENDAHULUAN}

Indonesia merupakan salah satu negara yang menerapkan sistem keuangan ganda (dual banking system). Sistem tersebut dimulai dengan diterbitkannya Undang-undang (UU) Nomor 7 tahun 1992 tentang perbankan dan Peraturan Permerintah Nomor 72 tahun 1992 mengenai dasar operasional bank bagi hasil. Beberapa tahun berikutnya, diterbitkan UU Nomor 10 Tahun 1998 sebagai amandemen UU Nomor 7 Tahun 1992, yang memberikan landasan hukum keberadaan sistem perbankan syariah. Landasan hukum tersebut memperbolehkan bank konvensional untuk melakukan kegiatan usaha berdasarkan prinsip syariah dengan dibukanya Unit Usaha Syariah (UUS). Kemudian di tahun 1999 dikeluarkan UU Nomor 23 Tahun 1999 yang kemudian pada tahun 2004 diamandemen dengan UU Nomor 3 Tahun 2004 tentang Bank Indonesia. Undang-undang tersebut memberikan kewenangan bagi Bank Indonesia untuk menggunakan instrument moneter syariah dalam menjalankan tugasnya. 
JAAKFE 2

Vol.10, No.1 des 2020, hal 1-9

Ilhamadi

Berdasarkan data statistik yang dikeluarkan OJK, per Juni 2019 total aset keuangan syariah Indonesia mencapai Rp 1.335,41 triliun dengan market share sebesar 8,29. Perbankan syariah masih mendominasi industri keuangan syariah sebesar 37,39\%. Bahkan pertumbuhan perbankan syariah di atas pertumbuhan perbankan konvensional pada tahun 2018.Penyaluran pembiayaan perbankan syariah pada tahun 2018 sebesar Rp 342 triliun meningkat 12 persen dibandingkan tahun sebelumnya. Jumlah tersebut masih jauh jika dibandingkan dengan perbankan konvensional sebesar Rp 7.810 triliun rupiah. Jenis penyaluran pembiayaan pleh perbankan syariah didominasi pada peruntukan konsumsi sebesar 44 persen, 24 persen untuk investasi dan 32 persen untuk modal kerja. Perkembangan sistem keuangan syariah sudah sepatutnya mendorong pertumbuhan ekonomi suatu negara. Karena perannya sebagai sumber dana bagi kegiatan produktif. Hal ini dikarenakan jenis transaksi didasarkan pada transaksi jual beli barang dan jasa. Sebagai contoh transaksi murabahah yang berbasis jual beli barang dan jasa dan mudharabah yang merupakan sistem bagi hasil. Hal ini menunjukkan bahwa pembiayaan pada perbankan syariah akan mendorong meningkatnya sektor riil. Berbeda dengan sistem konvensional di mana transaksinya didasarkan pada pengenaan bunga. Bunga berfungsi sebagai harga dari sejumlah uang maupun harga dari kredit di pasar keuangan. Hal tersebut menyebabkan bunga sebagai penyebab terciptanya uang tanpa disertai terciptanya barang dan jasa di pasar.(Juhro, S.M., Darsono, 2018)

Secara makro, keberadaan bunga berdampak pada penurunan perekonomian. Hal tersebut dalam perspektif syariah, sistem berbasis bunga tidak berdampak pada pertumbuhan ekonomi karena bersifat semu karena tidak menggambarkan produktivitas dan kesejahteraan secara riil. Peningkatan volume transaksi tidak diikuti dengan meningkatnya daya beli masyarakat, bahkan menyebabkan terjadinya inflasi.(Juhro, S.M., Darsono, 2018).Penelitian mengenai kajian empiris mengenai pertumbuhan sektor keuangan dan pertumbuhan ekonomi memiliki beberapa apriori, pertama, perkembangan sektor keuangan menentukan pertumbuhan ekonomi dari sisi suplai. Kedua, pertumbuhan sektor keuangan mengikuti pertumbuhan ekonomi jika dilihat dari sisi permintaan. Ketiga, hubungan sebab akibat yang dua arah antara sektor keuangan dan pertumbuhan ekonomi. (Furqani \& Mulyany, 2009)

Perkembangan sistem perbankan syriah di Malaysia menunjukkan peran yang efektif mendorong pertumbuhan ekonomi dan akumulasi modal. Dalam hal ini keberadaan perbankan 
JAAKFE 3

Vol.10, No.1 des 2020, hal 1-9

Ilhamadi

syariah membentuk suplai barang dan jasa sehingga berdampak pada pertumbuhan output. Selain itu, keberadaan sektor keuangan juga meningkatkan akumulasi modal. Perbaikan dan peningkatan infrastruktur pada sektor perbankan syariah menjadi hal penting untuk mendorong pertumbuhan ekonomi. (Furqani \& Mulyany, 2009)

Hal berbeda terjadi pada negara-negara di Asia Barat dan Afrika Utara. Keberadaan sektor perbankan syariah tidak berdampak signifikan pada pertumbuhan ekonomi. Bahkan sebaliknya, bahwa perkembangan perbankan syariah diakibatkan oleh pertumbuhan ekonomi. (Johnson, 2013) Kajian mengenai dampak perbankan syariah terhadap pertumbuhan ekonomi menjadi hal yang menarik jika kita melihat lagi dari sisi penyaluran pembiayaan. Seperti disebutkan sebelumnya bahwa ketika perbankan menyalurkan pembiayaan sudah seharusnya akan mendorong peningkatan output baik barang maupun jasa. Sehingga perkembangan perbankan syariah dapat dapat dilihat dari sisi penyaluran pembiayaan benar-benar akan memiliki dampak pada pertumbuhan ekonomi. Selain itu, bagaimana perbandingan tingkat elastisitas antara perbankan syariah dan perbankan konvensional untuk melihat tingkat efektivitas penyaluran dana pada sektor ekonomi dari kedua perbankan tersebut yang berdampak pada pertumbuhan output nasional. Maka penelitian ini menjadi sangat penting dan menarik untuk menambah literatur kajian mengenai permasalahan tersebut.

\section{KAJIAN LITERATUR}

Sistem keuangan merupakan sistem yang menghubungkan pihak kelebihan dana dengan pihak kekurangan dana dengan mekanisme transfer keuangan. Perbankan merupakan salah satu lembaga yang berada pada sistem tersebut. Keberadaannya dapat mengefisienkan transaksi, biaya informasi dan menimimalkan resiko penempatan dana. (Pusat Riset dan Edukasi Bank Sentral Bank Indonesia, 2014).Aktivitas intermediasi ini juga menjadi penting untuk memungkinkan pihak yang kurang memiliki investasi produktif dapat membiayai pihak yang memiliki tingkat investasi produktif yang tinggi. Sehingga keberadaaan perbankan dapat mendorong peningkatan produksi barang dan jasa. (Mishkin, 2009). Perbankan syariah sebagai salah satu lembaga keuangan syariah dapat menjalankan perannya dalam menjaga keseimbangan permintaan dan penawaran barang dan jasa. Seperti diketahui bahwa harga akan meningkat jika 
JAAKFE 4

Vol.10, No.1 des 2020, hal 1-9

Ilhamadi

terjadi kelebihan permintaan, begitupun jika tingkat penawaran barang dan jasa relative berkurang dari tingkat permintaannya.

(Juhro, S.M., Darsono, 2018) mengutip dari (Vogel, Frank E., 1998) mengenai model kelembagaan keuangan syariah dalam operasionalnya dengan menjalankan prinsip bahwa return on capital tidak boleh tetap (fixed) dengan penetapan di awal. Dalam hal ini yang diperbolehkan berupa porsi dari total keuntungan yang dihasilkan dari usaha atau yang boleh tetap itu adalah nisbah bagi hasilnya. Kedua, tidak boleh dari satu pihak yang menanggung resiko sepenuhnya dari kerjasama yang dilakukan. Sistem keuangan syariah tidak mengenal pemisahan antara sektor keuangan dan sektor riil. Dalam hal ini sektor keuangan dalam definisi Islam terbatas pada pengelolaan arus keuangan, serta mekanisme pembiayaan berdasarkan transaksi jual beli dan investasi di pasar riil. Maka karakteristik perekonomian Islam adalah perekonomian riil, dimana segala aktivitas terkait dengan arus uang berdampak pada kegiatan ekonomi riil dari aktivitas investasi.

Kajian empiris yang dilakukan oleh para ekonom mengenai hubungan antara perkembangan sektor keuangan dengan pertumbuhan ekonomi telah banyak dilakukan. (Panicos O., 2016) mengungkapkan kebijakan pendalaman keuangan terutama pada perbankan memungkinkan terjadinya pertumbuhan ekonomi. Perbankan sebagai lembaga intermediasi cocok dalam model pertumbuhan endogen dengan kebijakan represi agar perbankan lebih banyak menyalurkan danannya pada sektor-sektor produktif. Sistem perbankan syariah yang salah satu tujuan syariahnya bagaimana meningkatkan kesejahteraan masyarakat. Kesejahteraan ini menggambarkan meningkatnya surplus konsumen dan produsen dalam perekonomian. (Wajdi Dusuki, 2008) menyatakan bahwa perbankan syariah memiliki dimensi yang melekat dengan pengentasan kemiskinan. Para pelaku usaha mikro lebih mudah mendapatkan akses untuk mendapatkan pembiayaan mikro yang didasarkan pada prinsip investasi. Sehingga memiliki peluang untuk meningkatkan tingkat produksinya.

(Sukmana \& Kassim, 2010) mengkaji transmisi kebijakan moneter yang berdampak pada sektor riil. Perbankan syariah memainkan peran penting dalam proses transmisi kebijakan moneter di Malaysia. Produk-produk keuangan syariah yang berbasis transaksi dan investasi menyebabkan transmisi kebijakan moneter berjalan secara efektif. Namun, yang permasalahan yang dihadapi perbankan syariah berupa besarnya ketergantungan bank syariah pada dana 
JAAKFE 5

Vol.10, No.1 des 2020, hal 1-9

Ilhamadi

simpanan nasabah. Hal tersebut menyebabkan adanya resiko komersial terutama pada simpanan bertenor pendek. Sehingga masih perlu dikembangkan pasar uang syariah sebagai sumber pendanaan lainnya bagi bank syariah untuk memitigasi resiko tersebut.

(Rashid, Yousaf, \& Khaleequzzaman, 2017) membandingkan peran perbankan syariah dan konvensional pada stabilitas keuangan di Pakistan. Perbankan syariah memiliki kinerja yang lebih baik dibandingkan dengan perbankan konvensional dan berkontribusi lebih besar pada stabilitas sektor keuangan. Hal tersebut menunjukkan keberadaan bank syariah berpotensi berdampak positif terhadap pertumbuhan ekonomi. (Abduh \& Azmi Omar, 2012) melakukan pengujian jangka pendek dan jangka panjang mengenai hubungan antara pertumbuhan perbankan syariah dan pertumbuhan ekonomi. Hubungan antara perkembangan perbankan syariah dan pertumbuhan ekonomi memiliki hubungan timbal balik yang positif. Hal ini juga menunjukkan peran perbankan syariah sebagai lembaga intermediasi berjalan efektif mengintermediasi pihak yang kelebihan dana dengan pihak yang kekurangan dana. Sebaliknya, pertumbuhan ekonomi juga dapat mendorong berkembangnya perbankan syariah.

(Ahmad, Shafique, \& Ahmad, 2015) mengutip (Scumpeter, 1983) mengemukakan pentingnya peran sistem perbankan untuk mendorong pembangunan ekonomi melalui pembiayaan investasi produktif. Begitupula hubungan antara pertumbuhan sistem keuangan syariah yang memiliki pengaruh signifikan terhadap pertumbuhan ekonomi (Abduh \& Azmi Omar, 2012).

Dari beberapa paparan teori dan hasil uji empiris di atas, dapat dihasilkan hipotesis sebagai berikut:

$\mathrm{H}_{1}$ : Perkembangan pembiayaan pada perbankan syariah berpengaruh signifikan terhadap pertumbuhan ekonomi di Indonesia

$\mathrm{H}_{2}$ : Perkembangan penyaluran kredit pada perbankan konvensional berpengaruh signifikan terhadap pertumbuhan ekonomi

\section{METODE PENELITIAN}

Peneltian ini menggunakan metode deskriptif asosiatif dengan pendekatan kuantitatif. Data yang digunakan dalam penelitian ini menggunakan data sekunder berupa total produk domestik bruto dari lapangan usaha di Indonesia, besaran pembiayaan pada perbankan syariah dan penyaluran kredit oleh perbankan konvensional dari tahun 2010 hingga 2019. Sumber data 
JAAKFE 6

Vol.10, No.1 des 2020, hal 1-9

Ilhamadi

didapatkan pada data statistik perbankan yang tersedia pada website Otoritas Jasa Keuangan untuk data penyaluran pembiayaan perbankan syariah dan penyaluran kredit yang dilakukan oleh perbankan konvensional. Untuk data Produk Domestik Bruto (PDB) lapangan usaha diperoleh pada website Badan Pusat Statistik.

Permodelan estimasi merupakan persamaan regresi data panel dengan variabel endogen PDB dan variabel eksogen masing-masing pembiayaan perbankan syariah dan kredit perbankan konvensional. Agar penelitian ini dapat membandingkan tingkat elastisitas antar variabel eksogen maka data ditranformasi dalam bentuk logaritma natural. Nilai elastisitas yang didapatkan menggambarkan tingkat efektivitas perbankan terhadap perekonomian nasional. Berikut model persamaan regresi data panel yang mengambarkan pengaruh perbankan syariah dan konvensional terhadap pertumbuhan ekonomi, sebagai berikut:

$$
\ln \_P D B_{t}=\alpha+\beta_{1} \ln \_P_{i t}+\beta_{2} \ln \_L_{i t}+\varepsilon_{i t}
$$

Variabel ln_PDB merupakan data PDB dengan satuan rupiah yang telah ditranformasi dalam bentuk logaritma natural. Kemudian ln_P adalah total pembiayaan perbankan syariah dalam satuan rupiah dan ln_L merupakan total kredit yang disalurkan perbankan konvensional dalam satuan rupiah. Kemudian kedua variabel tersebut juga ditransformasi dengan logaritma natural. Untuk $\beta$ merupakan koefisien determinasi $(\mathrm{k}=1,2), \alpha$ sebagai intersep persamaan regresi, serta $\varepsilon$ sebagai error term. Sementara i mewakili cross section dari sektor ekonomi dan t periode waktu pengamatan.

Persamaan regresi data panel terdapat tiga model pendekatan dalam estimasi, yaitu, common effect, fixed effect, dan random effect. Untuk memilih model terbaik dari pendekatan tersebut

dilakukan uji Chow dan Hausman. Uji Chow digunakan untuk memilih antara pendekatan common effect dan fixed effect. Hipotesis yang digunakan adalah $\mathrm{H}_{0}$ : model mengikuti common effect dan $\mathrm{H}_{1}$ : model mengikuti fixed effect. Sedangkan uji Hausman digunakan untuk memilih pendekatan fixed effect dan random effect. Hipotesis yag digunakan adalah $\mathrm{H}_{0}$ : model mengikuti random effect dan $\mathrm{H}_{1}$ : model mengikuti fixed effect.

\section{HASIL PENELITIAN DAN PEMBAHASAN}


JAAKFE 7

Vol.10, No.1 des 2020, hal 1-9

Ilhamadi

Sektor perbankan syariah di Indonesia dalam lima tahun terakhir mengalami pertumbuhan aset tiap tahunnya. Tiap tahun pertumbuhan aset perbankan syariah rata-rata di atas $10 \%$. Tahun 2015 tercatat aset perbankan syariah sebesar Rp 304 triliun. Kemudian di tahun 2018 meningkat menjadi menjadi Rp 490 triliun, dengan market share sebesar 5,95\% dari total aset perbankan secara nasional. Jumlah pembiayaan yang disalurkan juga mengalami peningkatan tiap tahunnya rata-rata di atas 10\%. Tercatat tahun 2015 total pembiayaan sebesar Rp 219 triliun dan meningkat menjadi Rp 329 triliun pada tahun 2018.. Penyaluran pembiayaan didominasi pada jenis pembiayaan konsumsi sebesar 44,07\%, disusul modal kerja dan investasi dengan besaran masing-masing 31,84\% dan investasi 24,10\%. Produk akad murabahan masih dominan sebesar 49,95\%, kemudian akad musyarakah, mudharabah, ijarah, qardh, istishna' masing-masing $42,74 \%, 4,29 \%, 3,25 \%, 2,75 \%$ dan $0,56 \%$ serta akad lainnya sebesar $0,28 \%$.

Perkembangan sektor perbankan yang positif juga dialami pada pertumbuhan ekonomi Indonesia dalam lima tahun terakhir. Rata-rata pertumbuhan ekonomi tiap tahunnya sebesar $8 \%$. Sektor tersier atau yang berkaitan dengan sektor jasa sebagai sektor terbesar yang menopang perekonomian dengan rata-rata pertahun sebesar $45 \%$ dari seluruh sektor ekonomi. Sektor sekunder yang merupakan sektor industri menopang perekonomian sebesar 33\% dan sektor primer seperti pertanian, perkebunan, perikanan dan sumber daya alam menopang perkonomian sebesar 22\% secara nasional. Perkembangan sektor perbankan dan pertumbuhan ekonomi, secara teori memiliki keterkaitan satu sama lainnya. Sektor keuangan, salah satunya perbankan merupakan sektor yang dapat mendorong pertumbuhan output secara nasional. Sebagai lembaga intermediasi, perbankan menyediakan sumber dana yang didapat dari pihak yang mengalami surplus untuk disalurkan pada sektor-sektor ekonomi yang membutuhkan dana untuk meningkatkan bisnisnya.

Untuk mendapatkan hubungan kedua fenomena tersebut dapat dibuktikan dari tahapan pengujian ekonometrika. Langkah pertama dilakukan pemilihan model pelalui uji Chow dan Hausman. Hasil uji Chow dengan nilai probabilitas Chi-Square kurang dari $\alpha$ 5\% menunjukkan model fixed effect lebih baik dibandingkan PLS. Kemudian uji Hausman dengan nilai probabilitas Chi-Square kurang dari $\alpha$ 5\% menunjukkan model terbaik adalah random effect dibandingkan fixed effect. 
JAAKFE 8

Vol.10, No.1 des 2020, hal 1-9

Ilhamadi

Kemudian hasil estimasi persamaan model dapat dilihat pada output yang disajikan pada tabel 1. Hasil uji estimasi menunjukkan nilai $\mathrm{R}^{2}$ sebesar 0,88 yang berarti variabel endogen dari permodelan dapat digambarkan oleh variabel eksogen pertumbuhan penyaluran pembiayaan dan penyaluran kredit sebesar $88 \%$. Sementara sisanya $2 \%$ digambarkan oleh error term. Sementara hasil uji $\mathrm{F}$ menunjukkan nilai probabilitas F-statistic kurang dari $\alpha$ 5\% yang menjelaskan perkembangan perbangan perbankan syariah berdapak positif terhadap pertumbuhan ekonomi.

Tabel 1. Hasil Estimasi Model Pengaruh Pertumbuhan Perbankan Syariah dan Konvensional terhadap Pertumbuhan Ekonomi.

\begin{tabular}{lccc}
\hline \multicolumn{1}{r}{ Variabel } & Coefficient & t-Statistic & Prob. \\
\hline Ln_F & 0.094373 & 2.282393 & $0.0243^{* *}$ \\
Ln_L & 0.240136 & 3.962284 & $0.0001^{*}$ \\
C & 9.395115 & 22.98777 & 0.0000 \\
\hline R-Squared & 0.880021 & & \\
Prob (F-statistic) & 0.000000 & & \\
\hline
\end{tabular}

Ket: Signifikan pada $*(1 \%), * *(5 \%)$

Pada hasil uji t statistik terlihat nilai probabilitas t-statistic ln_F kurang dari $\alpha$ 5\%. Hal ini menunjukkan bahwa secara parsial penyaluran pembiayaan perbankan syariah berdampak positif dan signifikan terhadap pertumbuhan ekonomi. Sementara dari nilai koefisien pada variabel ln_F menggambarkan tingkat elastisitas 0,09\%. Nilai tersebut menjelaskan bahwa ketika perbankan syariah meningkatkan penyaluran pembiayaan pada sektor riil sebesar $1 \%$, makak akan meningkatkan pertumbuhan output sebesar 0,09\%. Hasil uji t pada variabel ln_L menunjukkan nilai probabilitas kurand dari 5\%. Hal ini menunjukkan bahwa pertumbuhan kredit perbankan konvensional memiliki pengaruh positif yang signifikan terhadap pertumbuhan ekonomi. Sedangkan nilai koefisien variabel ln_L sebesar 0,24 menunjukkan tingkat elastisitas sebesar $0,24 \%$. Hal tersebut menunjukkan bahwa jika bank konvensional meningkatkan penyaluran kreditnya sebesar 1\% akan berdampak pada pertumbuhan ekonomi sebesar 0,24\%.

Berdasarkan hasil uji estimasi di atas menjelaskan pentingnya peran perbankan syariah dan perbankan konvensional terhadap peningkatan output secara nasional. Jika dilihat dari nilai elastisitasnya, perbankan syariah masih memiliki peran yang kurang efektif jika dibandingkan 
JAAKFE 9

Vol.10, No.1 des 2020, hal 1-9

Ilhamadi

dengan bank konvensional. Kecilnya nilai elastisitas perbankan syariah juga disebabkan masih kecilnya pangsa pasar bank syariah secara nasional yang hanya sedikit di atas 5\%. Selain itu, dengan hasil di atas menunjukkan bahwa keberadaan bank syariah dan konvensional tidak selalu menggantikan. Bahkan jika dilihat dari pengaruh positif tersebut menjelaskan keberadaannya saling melengkapi. Bagi pemerintah perlu untuk mengeluarkan kebijakan yang dapat mempercepat perkembangan sektor keuangan baik syariah maupun konvensional. Sehingga dengan kebijakan tersebut dapat meningkatkan PDB nasional di masing-masing sektor ekonomi.

\section{KESIMPULAN}

Perbankan syariah memiliki peran yang signifikan pada pertumbuhan ekonomi di Indonesia. Hal yang sama juga terjadi pada perbankan konvensional yang memiliki pengaruh positif yang signifikan terhadap pertumbuha ekonomi. Namun, nilai elastisitas yang lebih kecil dibandingkan perbankan konvensional. Hal tersebut menunjukkan bahwa bank konvensional masih lebih efektif dibandingkan dengan bank syariah dalam meningkatkan pertumbuah ekonomi. Selain itu keberadaan perbankan syariah dan konvensional tidak selalu menjadi pengganti satu sama lainnya. Para nasabah kebanyakan masih melihat keberadaan kedua lembaga keuangan tersebut saling melengkapi untuk memenuhi kebutuhan dana bagi para pelaku ekonomi.

\section{REFERENCES}

Abduh, M., \& Azmi Omar, M. (2012). Islamic banking and economic growth: the Indonesian experience. International Journal of Islamic and Middle Eastern Finance and Management, 5(1), 35-47. https://doi.org/10.1108/17538391211216811

Ahmad, N., Shafique, M. N., \& Ahmad, H. (2015). Does Islamic Banking System Contributes to Economic Development. Nigerian Chapter of Arabian Journal of Business and Management Review, 3(8), 1-5. https://doi.org/10.12816/0014522

Furqani, H., \& Mulyany, R. (2009). Islamic banking and economic growth: Empirical evidence from Malaysia. Journal of Economic Cooperation and Development, 30(2), 59-74.

Johnson, K. (2013). Scholarship @ Claremont The Role of Islamic Banking in Economic Growth. Retrieved from http://scholarship.claremont.edu/cmc_theses/642

Juhro, S.M., Darsono, F. S. dan A. S. (2018). Kebijakan Moneter Syariah Dalam Sistem Keuangan Ganda Teori dan Praktek (Muhammad Syafii Antonio, ed.). Retrieved from https://isbn.perpusnas.go.id/Account/SearchBuku?searchCat=Pengarang\&searchTxt=Solikin+ M

Mishkin, F. S. (2009). The Economics of Money, Banking and Financial Markets (Ninth Edit; Donna Battista, ed.). The United States of America.

Panicos O., D. and K. B. L. (2016). Financial Development, Economic Growth and Banking Sector Controls : Evidence from India Author ( $s)$ : Panicos O . Demetriades and Kul B . Luintel Published by: Wiley on behalf of the Royal Economic Society Stable URL: http://www.jstor.org/stable/22352. 106(435), 359-374. 
JAAKFE 10

Vol.10, No.1 des 2020, hal 1-9

Ilhamadi

Pusat Riset dan Edukasi Bank Sentral Bank Indonesia. (2014). Kebanksentralan Teori dan Praktik di Indonesia (Iskandar Simorangkir, ed.). Jakarta, Indonesia: Raja Grafindo.

Rashid, A., Yousaf, S., \& Khaleequzzaman, M. (2017). Does Islamic banking really strengthen financial stability? Empirical evidence from Pakistan. International Journal of Islamic and Middle Eastern Finance and Management, 10(2), 130-148. https://doi.org/10.1108/IMEFM-112015-0137

Scumpeter, J. A. (1983). The Theory of Economic Development. New Jersey: New Brunswick.

Sukmana, R., \& Kassim, S. H. (2010). Roles of the Islamic banks in the monetary transmission process in Malaysia. International Journal of Islamic and Middle Eastern Finance and Management, 3(1), 7-19. https://doi.org/10.1108/17538391011033834

Vogel, Frank E., S. L. H. (1998). Islamic Law and Finance: Religion, Risk, and Return. The Hague: Kluwer Law International.

Wajdi Dusuki, A. (2008). Banking for the poor: The role of Islamic banking in microfinance initiatives. Humanomics, 24(1), 49-66. https://doi.org/10.1108/08288660810851469 